\title{
Synthesis and Biological Evaluation N-(6,7-dimethoxynaphthalen-yl) sulfamide Derivatives as Novel Inhibitors of Angiogenesis and Tumor Growth
}

\section{Guangsen $\mathrm{Xu}^{1}$, Yi Zhou' ${ }^{1}$, Shengqiang Zhang ${ }^{1}$, Shichao $\mathrm{Ma}^{1}$, Fuming $\mathrm{Xu}^{1}, \mathrm{Hao} \mathrm{Xu}^{2 *}$ and Wenfang $\mathrm{Xu}^{1 *}$}

${ }^{1}$ Department of Medicinal Chemistry, School of Pharmaceutical Science, Shandong University, 44 West Wenhua Road, Ji'nan, Shandong 250012, P.R. China ${ }^{2}$ Department of Breast and Thyroid Surgery, Shandong Provincial Hospital Affiliated to Shandong University, 324 Jingwu-Weiqi Road, Ji'nan 250021, P.R. China

\begin{abstract}
A novel series of $N$-(6,7-dimethoxynaphthalen-yl)sulfamide derivatives, targeting to angiogenesis and tumor growth, were well synthesized. Of these compounds, XGS-15 exhibited potent inhibitory effect on the proliferation of HCT116, PLC, U266, ES-2 and HEPG-2 cells and excellent anti-angiogenesis activity in both human umbilical vein endothelial cell (HUVEC) tube formation assay and the rat thoracic aorta rings test. Besides, compound XGS-15 showed weak inhibitory effects on human umbilical vein endothelial cell with high $I_{50}(>200 \mu \mathrm{M})$. So we speculated that compound XGS-15 revealed selective cytotoxic effect on tumor cells without influencing normal cells at low micromole ranges.
\end{abstract}

Keywords: Angiogenesis; Antiproliferative; Human umbilical vein endothelial cell tube formation; Rat thoracic aorta rings; Inhibitor

\section{Introduction}

Tumor angiogenesis is a vital hallmark of cancer and a property of almost all types of solid tumors [1]. Tumors rely on blood vessels to acquire oxygen and nutrients for growth and for spreading to other organ. Consequently, cancer needs to induce angiogenesis, the process of neovascular blood accommodating [2-6]. As a consequence, structure-based drug design with the purpose of angiogenesis inhibitors is a potential approach for finding new antineoplastic drugs. This pathway aims to destroy the established tumor new vessels, resulting in the development of plentiful tumor cell necrosis [7,8]. Furthermore, The present study describes that angiogenesis inhibitors would be much more effective in chemotherapy of cancer when combined with conventional cytotoxic agents [9-11]. We speculated that one drug would optimize the treatment of cancer with reduced resistance to drugs, if it was possessed of both anti-angiogenesis and the cytotoxic activities, such as Endostatin [12], Sunitinib (SU11248) [13,14] and Sorafenib (BAY43-9006, receptor tyrosine kinase inhibitor) [15], etc. From the above, searching for small molecular entities with both antiangiogenesis activity and conventional anticancer property is our ultimate goal.

Hereon, we report the design, synthesis and pharmacological evaluation of $N$-(6,7-dimethoxynaphthalen-yl)sulfamide derivatives. More and more newfangled naphthalene-containing compounds with role of anti-angiogenic and anti-tumor growth have been studied with patience, and it has been proved the particular planar structure of naphthalene could interact specially with ATP binding site of protein kinases [16-19]. On that basis, we decided to select naphthalene as a hydrophobic domain of our target compounds. It is worth mentioning that a series of $N$-(4-hydroxy-3-mercaptonaphthalen-1yl)amide derivatives have been synthesized, of which the biological characterization revealed that the most active compound $6 \mathrm{~d}$ showed strong cytotoxic and anti-angiogenesis effect [20]. Recently, a sequence of $\mathrm{N}$-(3-((7H-purin-6-yl)thio)-4-hydroxynaphthalen-1-yl) sulfonamide derivatives have been reported by the same researchers. The most effective compound 9n displayed stronger inhibition of cancer cell propagation and angiogenesis than $6 \mathrm{~d}$ [21]. Hence we believed that the sulfonamide structure would contribute to obvious improvements in cytotoxicity, antitumor activity, and extensive biological activities relative to amide structure in medicinal chemistry [22-26].

In addition, a sequence of quinazoline derivatives with two methoxyl groups such as KRN633 and quinoline derivatives containing two methoxyl groups such as KRN951, which are more active in cell assay and reducing HUVEC growth, have been reported. Moreover, KRN633 and KRN951 reflect fine security, proved by nude mice assay [27-31]. Therefore, in an effort to search for small molecular entities with both anti-angiogenesis activities and conventional anticancer property for cancer treatment, we decided to design the 15 compounds with the structural features of the 9n, KRN633 and KRN951. Of these target compounds, XGS-15 exerts the most powerful inhibitory effects on proliferation of various tumor cell strains and manifested competitive in anti-angiogenic activities to Pazopanib [32,33]. In both human umbilical vein endothelial cell (HUVEC) planar tube formation assay $[34,35]$ and the rat thoracic aorta rings assay $[35,36]$.

\section{Chemistry}

Target compounds were synthesized by the experiment process in Scheme 1. Firstly, mesyl groups were introduced into naphthalene2,3-diol in presence of triethylamine and dichloromethane (DCM). Secondly, the nitro group was introduced in the circumstances with nitric acid and acetic anhydride. Thirdly, the two sulfonyl groups on compound 3 were eliminated by dimethyl sulfate and sodium hydroxide solution [32]. Then the nitro-group on compound 4 was deoxidized to the amino group by $\mathrm{Pd}-\mathrm{C} / \mathrm{H}_{2}$ in methanol solution to give compound 5 [33], which was treated with various substituted sulfonyl chlorides to generate compounds XGS-1 to XGS-15 [34]. Analytic and spectral of the whole series compounds are in total accordance to the proposed structures.

*Corresponding authors: Wenfang $\mathrm{Xu}$, Department of Medicinal Chemistry School of Pharmaceutical Science, Shandong University, 44 West Wenhua Road, Ji'nan, Shandong 250012, P.R. China, Tel/Fax: +86 531 88382264; E-mail: wenfxu@gmail.com

Hao Xu, Department of Breast and Thyroid Surgery, Shandong Provincial Hospita Affiliated to Shandong University, 324 Jingwu-Weiqi Road, Ji'nan 250021, P.R. China, E-mail: drxuhao@163.com

Received July 05, 2014; Accepted August 11, 2014; Published August 11, 2014 Citation: Xu G, Zhou Y, Zhang S, Ma S, Xu F, et al. (2014) Synthesis and Biological Evaluation N-(6,7-dimethoxynaphthalen-yl) sulfamide Derivatives as Novel Inhibitors of Angiogenesis and Tumor Growth. Med chem 4: 598-605. doi:10.4172/2161-0444.1000200

Copyright: @ 2014 Xu G, et al. This is an open-access article distributed under the terms of the Creative Commons Attribution License, which permits unrestricted use, distribution, and reproduction in any medium, provided the original author and source are credited. 


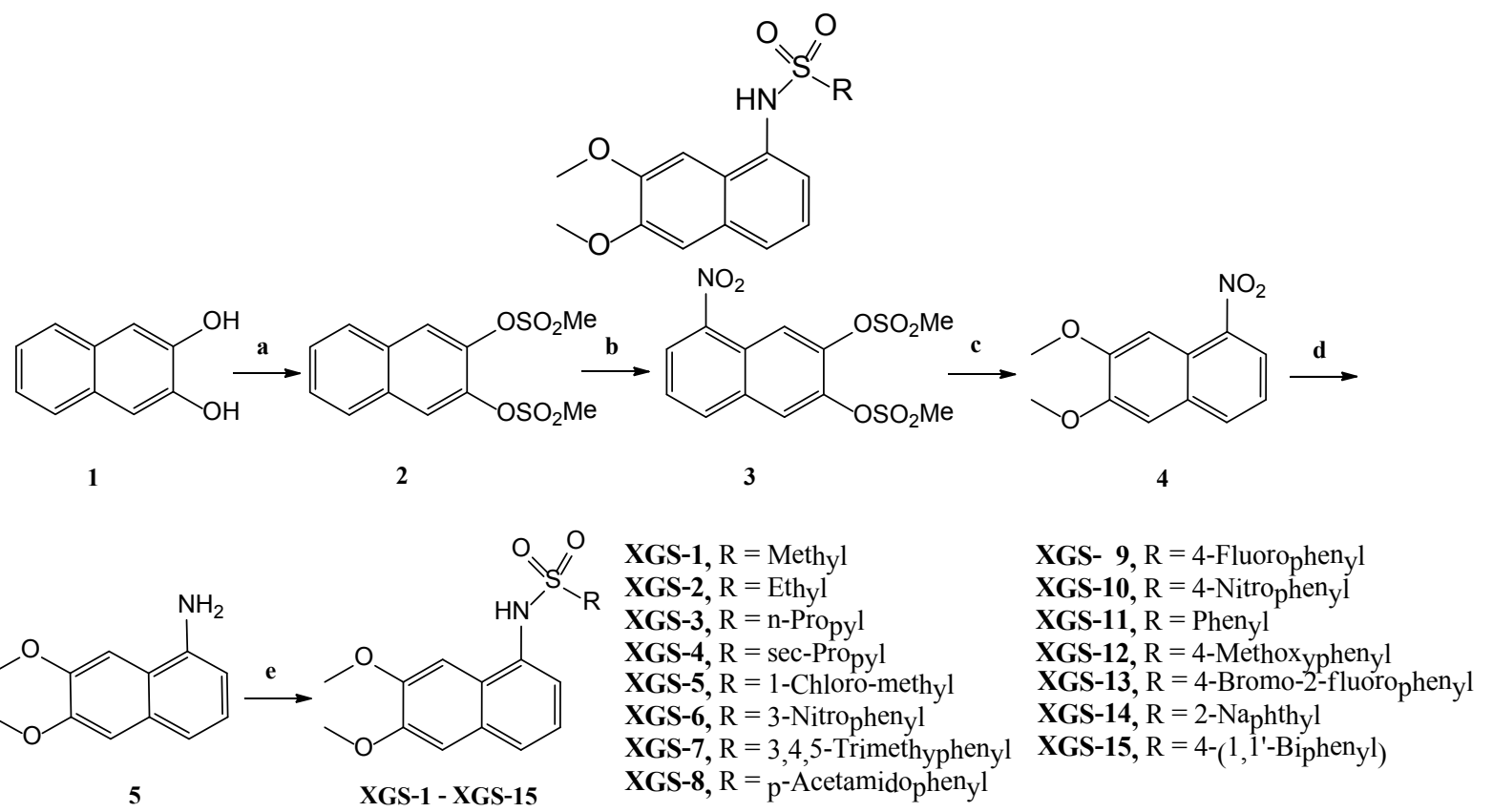

Scheme 1: Reagents and conditions: (a) $\mathrm{Et}_{3} \mathrm{~N}, \mathrm{CH}_{2} \mathrm{Cl}_{2}, \mathrm{MeSO}_{2} \mathrm{Cl}$; (b) $\mathrm{Ac}_{2} \mathrm{O}$, concentrated $\mathrm{HNO}_{3}$; (c) $2 \% \mathrm{NaOH}, \mathrm{Me}_{2} \mathrm{SO}_{4}$; (d) $\mathrm{Pd} / \mathrm{C}, \mathrm{H}_{2}, \mathrm{MeOH}$; (e) Pyridine, substituted sulfonyl chlorides, $0^{\circ} \mathrm{C}$.

\section{Materials and Methods}

Only if otherwise mentioned, all solvents and reagents were commercially available and utilized without any purification. Entire reactions were monitored by thin-layer chromatography on 0.25 $\mathrm{mm}$ silica gel plates (60 GF-254) and visualized with iodine vapor or under ultraviolet light. Proton NMR spectrums were determined on a Brucker DRX spectrometer $(600 / 300 \mathrm{MHz})$, carbon NMR spectrums on a AV300 spectrometer $(75 \mathrm{MHz}), \delta$ in parts per million and $\mathrm{J}$ in Hertz, using TMS as an internal standard. Measurements were made in DMSO- $\mathrm{d}_{6}$ solutions. ESI-MS were determined on an API 4000 spectrometer. Melting points were determined on an electrothermal melting point apparatus and were uncorrected.

Naphthalene-2,3-diyl dimethanesulfonate, 5-nitronaphthalene2,3-diyl dimethanesulfonate, 6,7-dimethoxy-1-nitronaphthalene and 6,7-dimethoxynaphthalen-1-amine were synthesized by the procedures mentioned previously.

\section{Naphthalene-2,3-dimethanesulfonate (Compound 2)}

Mp (melting point): $155-156^{\circ} \mathrm{C} ;{ }^{1} \mathrm{H}-\mathrm{NMR}$ (DMSO-d $\left.\mathrm{d}_{6}\right) \delta 3.57$ (s, $\left.6 \mathrm{H}, 2 \times-\mathrm{OSO}_{2} \mathrm{CH} 3\right), 7.63-7.67(\mathrm{~m}, 2 \mathrm{H}$, aromatic $\mathrm{H}), 8.03-8.07(\mathrm{~m}, 2 \mathrm{H}$, aromatic $\mathrm{H}), 8.18(\mathrm{~s}, 2 \mathrm{H}$, aromatic $\mathrm{H})$. MS-ESI+ m/z: $339.4[\mathrm{M}+\mathrm{Na}]^{+}$.

\section{5-Nitronaphthalene-2,3-dimethanesulfonate (Compound 3)}

Mp: $192-193^{\circ} \mathrm{C} ;{ }^{1} \mathrm{H}-\mathrm{NMR}\left(\mathrm{DMSO}-\mathrm{d}_{6}\right) \delta 3.62\left(\mathrm{~s}, 3 \mathrm{H},-\mathrm{OSO}_{2} \mathrm{CH}_{3}\right.$ ), $3.63\left(\mathrm{~s}, 3 \mathrm{H},-\mathrm{OSO}_{2} \mathrm{CH}_{3}\right), 7.83-7.87(\mathrm{~m}, 2 \mathrm{H}$, aromatic $\mathrm{H}), 8.46(\mathrm{~s}, 1 \mathrm{H}$, aromatic $\mathrm{H}), 8.50(\mathrm{t}, J=7.96 \mathrm{~Hz}, 1 \mathrm{H}$, aromatic $\mathrm{H}), 8.58(\mathrm{~s}, \mathrm{H}$, aromatic H). MS-ESI+ m/z: $384.3[\mathrm{M}+\mathrm{Na}]^{+}$.

\section{6,7-Dimethoxy-1-nitronaphthalene (Compound 4).}

Mp: $150-153^{\circ} \mathrm{C} ;{ }^{1} \mathrm{H}-\mathrm{NMR}\left(\mathrm{DMSO}_{6} \mathrm{~d}_{6}\right) \delta 3.90\left(\mathrm{~s}, 3 \mathrm{H},-\mathrm{OCH}_{3}\right), 3.91$ $\left(\mathrm{s}, 3 \mathrm{H},-\mathrm{OCH}_{3}\right), 7.47(\mathrm{t}, J=7.80 \mathrm{~Hz}, 1 \mathrm{H}$, aromatic $\mathrm{H}), 7.55(\mathrm{~s}, 1 \mathrm{H}$, aromatic $\mathrm{H}), 7.78(\mathrm{~s}, 1 \mathrm{H}$, aromatic $\mathrm{H}), 8.12-8.16(\mathrm{~m}, 2 \mathrm{H}$, aromatic $\mathrm{H})$. MS-ESI+ m/z: $234.4[\mathrm{M}+\mathrm{H}]^{+}$.

\section{6,7-Dimethoxynaphthalen-1-amine (Compound 5)}

Purified by column chromatography witH, EtOAc/petro ether as a pale pink crystal, yield: $67 \%$; Mp: $231-234^{\circ} \mathrm{C}$; ${ }^{1} \mathrm{H}-\mathrm{NMR}$ (DMSO- $\mathrm{d}_{6}$ ' AV300, $300 \mathrm{MHz}) \delta 3.90\left(\mathrm{~s}, 3 \mathrm{H},-\mathrm{OCH}_{3}\right), 3.94\left(\mathrm{~s}, 3 \mathrm{H},-\mathrm{OCH}_{3}\right), 7.33-$ $7.54(\mathrm{~m}, 3 \mathrm{H}$, aromatic $\mathrm{H}), 7.56(\mathrm{~s}, 1 \mathrm{H}$, aromatic $\mathrm{H}), 7.67(\mathrm{~d}, J=6.20 \mathrm{~Hz}$, aromatic $\mathrm{H}), 10.54\left(\mathrm{~s}, 2 \mathrm{H},-\mathrm{NH}_{2}\right) .{ }^{13} \mathrm{C} \mathrm{NMR}(150 \mathrm{MHz}) \delta 150.23,130.33$, $127.91,126.53,124.00,122.557,118.50,110.00,102.15,56.23,56.187$. HRMS-ESI+ m/z: $204.1018[\mathrm{M}+\mathrm{H}]^{+}$.

\section{General procedure for the preparation of XGS-1-XGS-15}

Bathed in ice water, 6,7-dimethoxynaphthalen-1-amine chloride $(3.58 \mathrm{~g}, 10 \mathrm{mmol})$ was dissolved in pyridine $(50 \mathrm{~mL})$. And by the time substituted sulfonyl hydrochloride $(12 \mathrm{mmol})$ was added drop by drop, the mixture was stirred at room temperature for $6 \mathrm{~h}$ (detected by TLC). Solvents were neutralized with hydrochloric acid (6 M) in condensate trap and then extracted by acetic ether for three times. The organic layer was washed with distilled water $(20 \mathrm{ml})$ and saturated sodium chloride solution $(20 \mathrm{ml})$ both for twice, dried over anhydrous magnesium sulfate and evaporated under vacuum. The residues were purified by column chromatography with EtOAc/petro ether to give desire intermediate XGS-1 to 15 as to white or yellowish powder.

\section{$\mathrm{N}$-(6,7-dimethoxynaphthalen-1-yl)methanesulfonamide (XGS-} 1).

Purified by column chromatography with EtOAc/petro ether as a pale pink crystal, yield: $78 \%$; Mp: $190-193^{\circ} \mathrm{C} ;{ }^{1} \mathrm{H}$ NMR (DMSO-d 6 ) $\delta$ 2.29 (s, $\left.3 \mathrm{H},-\mathrm{SO}_{2} \mathrm{CH}_{3}\right), 3.70\left(\mathrm{~s}, 3 \mathrm{H},-\mathrm{OCH}_{3}\right), 3.83\left(\mathrm{~s}, 3 \mathrm{H},-\mathrm{OCH}_{3}\right), 7.13$ $(\mathrm{d}, J=7.20 \mathrm{~Hz}, 1 \mathrm{H}$, aromatic $\mathrm{H}), 7.31-7.34(\mathrm{~m}, 1 \mathrm{H}$, aromatic $\mathrm{H}), 7.55$ $(\mathrm{d}, J=7.80 \mathrm{~Hz}, 2 \mathrm{H}$, aromatic $\mathrm{H}), 7.66(\mathrm{~d}, J=7.20 \mathrm{~Hz}, 1 \mathrm{H}$, aromatic $\mathrm{H})$, 10.04 (s, $1 \mathrm{H},-\mathrm{NH}-) .{ }^{13} \mathrm{C}$ NMR (DMSO-d $) ~ \delta 149.55,149.40,131.63$, $129.99,124.86,124.67,123.69,121.07,106.84,102.35,40.33,40.05$, 39.78. HRMS-ESI+ m/z: $304.0617[\mathrm{M}+\mathrm{Na}]^{+}$.

\section{$\mathrm{N}$-(6,7-dimethoxynaphthalen-1-yl)ethanesulfonamide (XGS-2).}

Purified by column chromatography with EtOAc/petro ether as a 
white crystal, yield: $76 \%$; Mp: $160-161^{\circ} \mathrm{C} ;{ }^{1} \mathrm{H}$ NMR (DMSO-d $) \delta 1.24$ $\left(\mathrm{t}, J=7.20 \mathrm{~Hz}, 3 \mathrm{H},-\mathrm{CH}_{2}-\right), 3.06\left(\mathrm{q}, J=7.20 \mathrm{~Hz}, 2 \mathrm{H},-\mathrm{CH}_{3}\right), 3.88(\mathrm{~s}, 3 \mathrm{H}$, $\left.-\mathrm{OCH}_{3}\right), 3.91\left(\mathrm{~s}, 3 \mathrm{H},-\mathrm{OCH}_{3}\right), 7.29(\mathrm{t}, J=7.80 \mathrm{~Hz}, 1 \mathrm{H}$, aromatic $\mathrm{H})$, 7.34-7.35 (m, $2 \mathrm{H}$, aromatic $\mathrm{H}), 7.63-7.65(\mathrm{~m}, 2 \mathrm{H}$, aromatic $\mathrm{H}), 9.62$ $(\mathrm{s}, 1 \mathrm{H},-\mathrm{NH}-) .{ }^{13} \mathrm{C}$ NMR (DMSO-d $) \delta 149.48,149.36,131.67,129.96$, 124.57, 124.33, 123.69, 120.31, 106.88, 102.26, 55.51, 55.44, 45.91, 8.13. HRMS-ESI+ m/z: $318.0769[\mathrm{M}+\mathrm{Na}]^{+}$.

$\mathrm{N}$-(6,7-dimethoxynaphthalen-1-yl)propane-1-sulfonamide (XGS-3).

Purified by column chromatography with EtOAc/petro ether as a yellowish crystal, yield: $65 \%$; Mp: $120-121^{\circ} \mathrm{C} ;{ }^{1} \mathrm{H}$ NMR (DMSO-d 6 ) $\delta$ $0.90\left(\mathrm{t}, J=7.20 \mathrm{~Hz}, 3 \mathrm{H},-\mathrm{CH}_{3}\right), 1.70-1.76\left(\mathrm{~m}, 2 \mathrm{H},-\mathrm{CH}_{2}-\right), 3.03(\mathrm{t}, J=$ $\left.7.80 \mathrm{~Hz}, 2 \mathrm{H},-\mathrm{CH}_{2}-\right), 3.88\left(\mathrm{~s}, 3 \mathrm{H},-\mathrm{OCH}_{3}\right), 3.91\left(\mathrm{~s}, 3 \mathrm{H},-\mathrm{OCH}_{3}\right), 7.30(\mathrm{t}, J$ $=7.80 \mathrm{~Hz}, 1 \mathrm{H}$, aromatic $\mathrm{H}), 7.34(\mathrm{~d}, J=9.0 \mathrm{~Hz}, 2 \mathrm{H}$, aromatic $\mathrm{H}), 7.62-$ $7.65(\mathrm{~m}, 2 \mathrm{H}$, aromatic $\mathrm{H}), 9.63(\mathrm{~s}, 1 \mathrm{H},-\mathrm{NH}-) .{ }^{13} \mathrm{C}$ NMR (DMSO-d $)$ $\delta 149.47,149.35,131.6,129.96,124.56,124.31,123.70,120.35,106.88$, $102.24,40.34,40.06,16.96,12.64$; HRMS-ESI+ m/z: $310.1159[\mathrm{M}+\mathrm{H}]^{+}$.

$\mathrm{N}$-(6,7-dimethoxynaphthalen-1-yl)propane-2-sulfonamide (XGS-4).

Purified by column chromatography with EtOAc/petro ether as a yellowish crystal, yield: $75 \%$; Mp: $161-163^{\circ} \mathrm{C} ;{ }^{1} \mathrm{H}$ NMR (DMSO-d $\left.{ }_{6}\right) \delta$ $1.26\left(\mathrm{~d}, J=7.20 \mathrm{~Hz}, 6 \mathrm{H}, 2 \times-\mathrm{CH}_{3}\right), 2.50(\mathrm{~m}, 1 \mathrm{H},-\mathrm{CH}-), 3.88(\mathrm{~s}, 3 \mathrm{H}$, $\left.-\mathrm{OCH}_{3}\right), 3.90\left(\mathrm{~s}, 3 \mathrm{H},-\mathrm{OCH}_{3}\right), 7.28(\mathrm{t}, J=7.80 \mathrm{~Hz}, 1 \mathrm{H}$, aromatic $\mathrm{H}), 7.33$ $(\mathrm{s}, 1 \mathrm{H}$, aromatic $\mathrm{H}), 7.38(\mathrm{~d}, J=7.20 \mathrm{~Hz}, 1 \mathrm{H}$, aromatic $\mathrm{H}), 7.62(\mathrm{~d}, J=$ $7.80 \mathrm{~Hz}, 1 \mathrm{H}$, aromatic H), 7.65 (s, $1 \mathrm{H}$, aromatic $\mathrm{H}), 9.60$ (s, $1 \mathrm{H},-\mathrm{NH}-)$. ${ }^{13} \mathrm{C}$ NMR (DMSO-d $) \delta 149.41,149.31,132.01,129.94,124.27,123.99$, $123.69,119.76,106.93,102.31,55.51,55.44,52.20,16.44$. HRMS-ESI+ $\mathrm{m} / \mathrm{z}: 332.1168[\mathrm{M}+\mathrm{Na}]^{+}$.

1 - chloro- $N-(6,7-d i m e t h o x y n a p h t h a l e n-1-y l)$ methanesulfonamide (XGS-5).

Purified by column chromatography with EtOAc/petro ether as a yellowish crystal, yield: $73 \%$; Mp: $189-192^{\circ} \mathrm{C} ;{ }^{1} \mathrm{H}$ NMR (DMSO-d 6 ) $\delta$ $2.50\left(\mathrm{~m}, 1 \mathrm{H},-\mathrm{CH}_{2}-\right), 3.87\left(\mathrm{~s}, 3 \mathrm{H},-\mathrm{OCH}_{3}\right), 3.90\left(\mathrm{~s}, 3 \mathrm{H},-\mathrm{OCH}_{3}\right), 7.25-7.29$ $(\mathrm{m}, 2 \mathrm{H}$, aromatic $\mathrm{H}), 7.32(\mathrm{~s}, 1 \mathrm{H}$, aromatic $\mathrm{H}), 7.54(\mathrm{~s}, 1 \mathrm{H}$, aromatic $\mathrm{H})$, $7.14(\mathrm{~d}, J=7.80,1 \mathrm{H}) 9.82$ (s, $1 \mathrm{H},-\mathrm{NH}-) .{ }^{13} \mathrm{C}$ NMR (DMSO-d $)$ ) $\delta 149.44$, $149.37,136.90,131.01,129.89,126.49,124.91,124.71,123.57,121.30$, 106.79, 55.47, 55.44. HRMS-ESI+ m/z: $316.0670[\mathrm{M}+\mathrm{H}]^{+}$.

$\mathrm{N}$-(6,7-dimethoxynaphthalen-1-yl)-3-nitrobenzenesulfonamide (XGS-6).

Purified by column chromatography with EtOAc/petro ether as a white crystal, yield: $70 \%$; Mp: $196-198^{\circ} \mathrm{C}$; ${ }^{1} \mathrm{H}$ NMR (DMSO-d 6 ) $\delta 3.68$ $\left(\mathrm{s}, 3 \mathrm{H},-\mathrm{OCH}_{3}\right), 3.82\left(\mathrm{~s}, 3 \mathrm{H},-\mathrm{OCH}_{3}\right), 7.14(\mathrm{~d}, J=7.20 \mathrm{~Hz}, 1 \mathrm{H}$, aromatic $\mathrm{H}), 7.19(\mathrm{~s}, 1 \mathrm{H}$, aromatic $\mathrm{H}), 7.24-7.27(\mathrm{~m}, 2 \mathrm{H}$, aromatic $\mathrm{H}), 7.64(\mathrm{~d}, J$ $=7.80 \mathrm{~Hz}, 1 \mathrm{H}$, aromatic $\mathrm{H}), 7.75(\mathrm{t}, J=8.40 \mathrm{~Hz}, 1 \mathrm{H}$, aromatic $\mathrm{H}), 7.98$ $(\mathrm{d}, J=7.80 \mathrm{~Hz}, 1 \mathrm{H}$, aromatic $\mathrm{H}), 8.40-8.41(\mathrm{~m}, 2 \mathrm{H}), 10.44(\mathrm{~s}, 1 \mathrm{H},-\mathrm{NH}-$ ). ${ }^{13} \mathrm{C} \mathrm{NMR}(150 \mathrm{MHz}) \delta 149.82,148.10,142.09,133.08,131.73,130.59$, 127.76, 126.07, 125.04, 124.11, 122.77, 121.86, 110.00, 107.26, 55.84, 55.59; HRMS-ESI+ m/z: $389.0801[\mathrm{M}+\mathrm{H}]^{+}$.

$N-(6,7-d$ i m e th ox yn a ph thale n- 1 - yl $)-3,4,5-$ trimethylbenzenesulfonamide (XGS-7).

Purified by column chromatography with EtOAc/petro ether as a yellowish crystal, yield: $75 \%$; Mp: $160-161^{\circ} \mathrm{C} ;{ }^{1} \mathrm{H}$ NMR (DMSO-d ${ }_{6}$ ) $\delta$ $2.17(\mathrm{~s}, 3 \mathrm{H},-\mathrm{CH} 3), 2.37$ (s, 6H, $2 \times-\mathrm{CH} 3), 3.70\left(\mathrm{~s}, 3 \mathrm{H},-\mathrm{OCH}_{3}\right), 3.83(\mathrm{~s}$, $\left.3 \mathrm{H},-\mathrm{OCH}_{3}\right), 6.91(\mathrm{~s}, 2 \mathrm{H}$, aromatic $\mathrm{H}), 7.10(\mathrm{~d}, J=7.80 \mathrm{~Hz}, 1 \mathrm{H}$, aromatic $\mathrm{H}), 7.20-7.25(\mathrm{~m}, 3 \mathrm{H}$, aromatic $\mathrm{H}), 7.60(\mathrm{~d}, J=7.80 \mathrm{~Hz}, 1 \mathrm{H}$, aromatic $\mathrm{H}), 9.99$ (s, $1 \mathrm{H},-\mathrm{NH}-) .{ }^{13} \mathrm{C}$ NMR (DMSO-d $) ~ \delta 149.17,149.12,141.49$, $138.41,135.04,131.56,130.78,129.77,125.23,125.11,123.49,122.07$,
$106.65,102.01,55.33,54.96,22.65,22.26$. HRMS-ESI+ m/z: 408.1276 $[\mathrm{M}+\mathrm{Na}]^{+}$

$N$-(4-(N-(6,7-dimethoxynaphthalen-1-yl)sulfamoyl)phenyl) acetamide (XGS-8).

Purified by column chromatography with EtOAc/petro ether as a white crystal, yield: $78 \%$; Mp: $216-217^{\circ} \mathrm{C} ;{ }^{1} \mathrm{H}$ NMR (DMSO-d $\left.{ }_{6}\right) \delta 2.04$ $\left(\mathrm{s}, 3 \mathrm{H},-\mathrm{OCH}_{3}\right), 3.72\left(\mathrm{~s}, 3 \mathrm{H},-\mathrm{OCH}_{3}\right), 3.83\left(\mathrm{~s}, 3 \mathrm{H},-\mathrm{OCH}_{3}\right), 7.14(\mathrm{~d}, J$ $=7.20 \mathrm{~Hz}, 1 \mathrm{H}$, aromatic $\mathrm{H}), 7.22(\mathrm{~s}, 1 \mathrm{H}$, aromatic $\mathrm{H}), 7.23-7.24(\mathrm{~m}$, $2 \mathrm{H}$, aromatic $\mathrm{H}), 7.56-7.59(\mathrm{~m}, 3 \mathrm{H}$, aromatic $\mathrm{H}), 7.62(\mathrm{~d}, J=9.60 \mathrm{~Hz}$, $2 \mathrm{H}$, aromatic $\mathrm{H}$ ), 10.00 (s, $1 \mathrm{H},-\mathrm{NH}-), 10.25$ (s, $1 \mathrm{H},-\mathrm{NH}-) .{ }^{13} \mathrm{C}$ NMR $\left(\right.$ DMSO-d $\left._{6}\right) \delta 168.91,149.11,142.85,133.90,131.46,131.08,129.77$, $128.62,127.81,124.88,124.58,123.52,121.76,118.37,106.65,102.18$, 64.98, 55.33, 55.19; HRMS-ESI+ m/z:401.1250 [M+H] $]^{+}$.

$N-(6,7-d i m e t h$ ox y a pht h a 1 e n - 1 - y 1$)-4$ fluorobenzenesulfonamide (XGS-9).

Purified by column chromatography with EtOAc/petro ether as a white crystal, yield: $66 \%$; Mp: $171-172{ }^{\circ} \mathrm{C} ;{ }^{1} \mathrm{H}$ NMR (DMSO-d $) ~ \delta 3.71$ $\left(\mathrm{s}, 3 \mathrm{H},-\mathrm{OCH}_{3}\right), 3.83\left(\mathrm{~s}, 3 \mathrm{H},-\mathrm{OCH}_{3}\right), 7.13(\mathrm{~d}, J=7.80 \mathrm{~Hz}, 1 \mathrm{H}$, aromatic $\mathrm{H}), 7.17(\mathrm{~s}, 1 \mathrm{H}$, aromatic $\mathrm{H}), 7.23-7.25(\mathrm{~m}, 1 \mathrm{H}$, aromatic $\mathrm{H}), 7.31(\mathrm{t}, J$ $=9.0 \mathrm{~Hz}, 2 \mathrm{H}$, aromatic $\mathrm{H}), 7.61(\mathrm{~d}, J=8.40 \mathrm{~Hz}, 1 \mathrm{H}$, aromatic $\mathrm{H}), 7.67-$ $7.69(\mathrm{~m}, 2 \mathrm{H}$, aromatic $\mathrm{H}), 10.15(\mathrm{~s}, 1 \mathrm{H},-\mathrm{NH}-) .{ }^{13} \mathrm{C}$ NMR (DMSO-d $) ~ \delta$ $149.22,149.16,136.64,130.72,129.81,129.69,129.56,125.19,124.62$, $123.55,122.02,116.36,116.05,106.72,101.94,55.36,55.21$; HRMS$\mathrm{ESI}+\mathrm{m} / \mathrm{z}: 384.1045[\mathrm{M}+\mathrm{Na}]^{+}$.

$\mathrm{N}$-(6,7-dimethoxynaphthalen-1-yl)-4-nitrobenzenesulfonamide (XGS-10).

Purified by column chromatography with EtOAc/petro ether as a off-white crystal, yield: $78 \%$; Mp: $247-249^{\circ} \mathrm{C} ;{ }^{1} \mathrm{H}$ NMR (DMSO- $\mathrm{d}_{6}$ ) $\delta$ $3.71\left(\mathrm{~s}, 1 \mathrm{H},-\mathrm{OCH}_{3}\right), 3.83\left(\mathrm{~s}, 1 \mathrm{H},-\mathrm{OCH}_{3}\right), 3.71(\mathrm{~s}, 1 \mathrm{H}$, aromatic $\mathrm{H}), 7.12$ $(\mathrm{d}, J=7.80 \mathrm{~Hz}, 1 \mathrm{H}$, aromatic $\mathrm{H}), 7.19(\mathrm{~s}, 1 \mathrm{H}$, aromatic $\mathrm{H}), 7.19-7.27$ $(\mathrm{m}, 2 \mathrm{H}$, aromatic $\mathrm{H}), 7.63(\mathrm{~d}, J=8.40 \mathrm{~Hz}, 1 \mathrm{H}$, aromatic $\mathrm{H}), 7.91(\mathrm{~d}, J=$ $5.40 \mathrm{~Hz}, 2 \mathrm{H}$, aromatic $\mathrm{H}), 8.31(\mathrm{~d}, J=7.20 \mathrm{~Hz}, 2 \mathrm{H}$, aromatic $\mathrm{H}), 10.55$ (s, $1 \mathrm{H},-\mathrm{NH}-) .{ }^{13} \mathrm{C}$ NMR (DMSO-d $) \delta 149.62,149.37,149.26,145.82$, $130.14,129.86,128.29,125.53,124.67,124.45,123.60,122.14,106.79$, 101.79, 55.37, 55.25. HRMS-ESI+ m/z: $411.0671[\mathrm{M}+\mathrm{Na}]^{+}$.

\section{$\mathrm{N}$-(6,7-dimethoxynaphthalen-1-yl)benzenesulfonamide (XGS- 11).}

Purified by column chromatography with EtOAc/petro ether as a yellowish crystal, yield: $65 \%$; Mp: $169-174^{\circ} \mathrm{C} ;{ }^{1} \mathrm{H}$ NMR $\left(\right.$ DMSO- $\left.\mathrm{d}_{6}\right) \delta$ $3.68\left(\mathrm{~s}, 3 \mathrm{H},-\mathrm{OCH}_{3}\right), 3.82\left(\mathrm{~s}, 3 \mathrm{H},-\mathrm{OCH}_{3}\right), 7.15(\mathrm{~d}, J=6.60 \mathrm{~Hz}, 2 \mathrm{H}$, aromatic $\mathrm{H}), 7.24(\mathrm{t}, J=7.80 \mathrm{~Hz}, 2 \mathrm{H}$, aromatic $\mathrm{H}), 7.45(\mathrm{t}, J=7.80$ $\mathrm{Hz}, 2 \mathrm{H}$, aromatic $\mathrm{H}), 7.55(\mathrm{t}, J=7.80 \mathrm{~Hz}, 1 \mathrm{H}$, aromatic $\mathrm{H}), 7.59(\mathrm{~d}, J=$ $7.80 \mathrm{~Hz}, 1 \mathrm{H}$, aromatic $\mathrm{H}), 7.64(\mathrm{~d}, J=7.20 \mathrm{~Hz}, 2 \mathrm{H}$, aromatic $\mathrm{H}), 10.12$ (s, 1H, -NH-). ${ }^{13} \mathrm{C}$ NMR (DMSO-d $) \delta 149.13,140.30,132.55,130.89$, $129.77,129.04,126.57,125.04,124.59,123.51,121.91,106.66,102.03$, 55.33, 55.18, ; HRMS-ESI+ m/z: $366.1007[\mathrm{M}+\mathrm{Na}]^{+}$.

$N-(6,7-d i m e t h$ ox y a pht halen-1-yl)- 4 methyloxybenzenesulfonamide (XGS-12).

Purified by column chromatography with EtOAc/petro ether as a white crystal, yield: $80 \%$; Mp: $157-160^{\circ} \mathrm{C} ;{ }^{1} \mathrm{H}$ NMR (DMSO-d ${ }_{6}$ ) $\delta 3.73$ (s, $\left.3 \mathrm{H},-\mathrm{OCH}_{3}\right), 3.75\left(\mathrm{~s}, 3 \mathrm{H},-\mathrm{OCH}_{3}\right), 3.83\left(\mathrm{~s}, 3 \mathrm{H},-\mathrm{OCH}_{3}\right), 6.98(\mathrm{~d}, J=$ $7.80 \mathrm{~Hz}, 1 \mathrm{H}$, aromatic $\mathrm{H}), 7.13(\mathrm{~d}, J=7.20 \mathrm{~Hz}, 1 \mathrm{H}$, aromatic $\mathrm{H}), 7.20$ $7.23(\mathrm{~m}, 3 \mathrm{H}$, aromatic $\mathrm{H}), 7.24(\mathrm{~d}, J=7.80 \mathrm{~Hz}, 2 \mathrm{H}$, aromatic $\mathrm{H}), 7.58(\mathrm{~d}$, $J=8.40 \mathrm{~Hz}, 2 \mathrm{H}$, aromatic $\mathrm{H}), 9.96(\mathrm{~s}, 1 \mathrm{H},-\mathrm{NH}-) .{ }^{13} \mathrm{C} \mathrm{NMR}\left(\mathrm{DMSO}-\mathrm{d}_{6}\right)$ $\delta 162.23,149.14,132.01,131.46,131.18,129.78,128.78,124.81,124.52$, $123.51,121.52,114.17,106.67,102.16,55.56,55.34,55.23$; HRMS-ESI+ $\mathrm{m} / \mathrm{z}: 396.1128[\mathrm{M}+\mathrm{Na}]^{+}$. 
4-bromo- $N$ - (6, 7 -dimethoxynaphthalen-1-yl)- 2 fluorobenzenesulfonamide (XGS-13).

Purified by column chromatography with EtOAc/petro ether as a pink crystal, yield: $75 \%$; Mp: $171-172{ }^{\circ} \mathrm{C} ;{ }^{1} \mathrm{H}$ NMR (DMSO-d $) \delta 3.78$ $\left(\mathrm{s}, 3 \mathrm{H},-\mathrm{OCH}_{3}\right), 3.84\left(\mathrm{~s}, 3 \mathrm{H},-\mathrm{OCH}_{3}\right), 7.18(\mathrm{~d}, J=7.2 \mathrm{~Hz}, 1 \mathrm{H}), 7.23-7.27$ $(\mathrm{m}, 2 \mathrm{H}), 7.34(\mathrm{~s}, 1 \mathrm{H}$, aromatic $\mathrm{H}), 7.48(\mathrm{~d}, J=9.60 \mathrm{~Hz}, 1 \mathrm{H}$, aromatic $\mathrm{H})$, $7.55(\mathrm{t}, J=8.40 \mathrm{~Hz}, 1 \mathrm{H}$, aromatic $\mathrm{H}), 7.62(\mathrm{~d}, J=7.80 \mathrm{~Hz}, 1 \mathrm{H}$, aromatic $\mathrm{H}), 7.81(\mathrm{~d}, J=9.60 \mathrm{~Hz}, 1 \mathrm{H}$, aromatic $\mathrm{H}), 10.64(\mathrm{~s}, 1 \mathrm{H},-\mathrm{NH}-) .{ }^{13} \mathrm{C} \mathrm{NMR}$ $\left(\right.$ DMSO-d $\left._{6}\right) \delta 159.72,156.29,149.38,131.41,130.02,129.78,128.14$, $127.67,127.55,127.40,125.43,124.77,123.58,121.92,120.79,120.46$, 106.81, 101.63, 55.39, 55.13; HRMS-ESI+ m/z: $441.9959[\mathrm{M}+\mathrm{H}]^{+}$.

$\mathrm{N}$-(6,7-dimethoxynaphthalen-1-yl)naphthalene-2-sulfonamide (XGS-14).

Purified by column chromatography with EtOAc/petro ether as a lavender crystal, yield: $68 \%$; Mp: $193-196^{\circ} \mathrm{C} ;{ }^{1} \mathrm{H}$ NMR (DMSO-d $) \delta$ $3.59\left(\mathrm{~s}, 3 \mathrm{H},-\mathrm{OCH}_{3}\right), 3.78\left(\mathrm{~s}, 3 \mathrm{H},-\mathrm{OCH}_{3}\right), 7.17(\mathrm{dd}, J=7.20 \mathrm{~Hz}, 1.20 \mathrm{~Hz}$, $1 \mathrm{H}$, aromatic $\mathrm{H}), 7.20-7.21(\mathrm{~m}, 2 \mathrm{H}$, aromatic $\mathrm{H}), 7.23(\mathrm{~s}, 1 \mathrm{H}$, aromatic $\mathrm{H}), 7.57(\mathrm{~d}, J=8.40 \mathrm{~Hz}, 1 \mathrm{H}$, aromatic $\mathrm{H}), 7.61(\mathrm{~d}, J=7.20 \mathrm{~Hz}, 1 \mathrm{H}$, aromatic $\mathrm{H}), 7.65(\mathrm{t}, J=7.20 \mathrm{~Hz}, 1 \mathrm{H}$, aromatic $\mathrm{H}), 7.76(\mathrm{dd}, J=9.00$ $\mathrm{Hz}, 1.80 \mathrm{~Hz}, 1 \mathrm{H}$, aromatic $\mathrm{H}), 7.97(\mathrm{~d}, J=8.40 \mathrm{~Hz}, 1 \mathrm{H}$, aromatic $\mathrm{H})$, 8.01-8.04 (m, $2 \mathrm{H}$, aromatic $\mathrm{H}), 8.29(\mathrm{~s}, 1 \mathrm{H}$, aromatic $\mathrm{H}), 10.24(\mathrm{~s}, 1 \mathrm{H}$, -NH-). ${ }^{13} \mathrm{C}$ NMR (DMSO-d $)$ ) $\delta 149.10,137.42,134.09,131.52,130.89$, $129.77,129.16,129.05,128.75,127.73,127.54,127.50,125.02,124.61$, $123.54,122.34,121.82,106.66,102.06,55.30,55.02$. HRMS-ESI+ m/z: $394.1159[\mathrm{M}+\mathrm{H}]^{+}$.

$N$-(6,7-dimethoxynaphthalen-1-yl) - [1,1'-biphenyl $]$-4sulfonamide (XGS-15).

Purified by column chromatography with EtOAc/petro ether as a yellowish crystal, yield: $67 \%$; Mp: $171-173^{\circ} \mathrm{C} ;{ }^{1} \mathrm{H}$ NMR (DMSO-d $\left.{ }_{6}\right) \delta$ $3.69\left(\mathrm{~s}, 3 \mathrm{H},-\mathrm{OCH}_{3}\right), 3.81\left(\mathrm{~s}, 3 \mathrm{H},-\mathrm{OCH}_{3}\right), 7.19-7.20(\mathrm{~m}, 2 \mathrm{H}$, aromatic $\mathrm{H}), 7.24-7.27(\mathrm{~m}, 2 \mathrm{H}$, aromatic $\mathrm{H}), 7.43(\mathrm{~d}, J=7.20 \mathrm{~Hz}, 1 \mathrm{H}$, aromatic $\mathrm{H}), 7.48(\mathrm{t}, J=7.20 \mathrm{~Hz}, 2 \mathrm{H}$, aromatic $\mathrm{H}), 7.61(\mathrm{~d}, J=7.80 \mathrm{~Hz}, 1 \mathrm{H}$, aromatic $\mathrm{H}), 7.65(\mathrm{~d}, J=7.20 \mathrm{~Hz}, 2 \mathrm{H}$, aromatic $\mathrm{H}), 7.72(\mathrm{~d}, J=8.40 \mathrm{~Hz}$, $2 \mathrm{H}$, aromatic $\mathrm{H}), 7.77(\mathrm{~d}, J=8.40 \mathrm{~Hz}, 2 \mathrm{H}$, aromatic $\mathrm{H}), 10.17(\mathrm{~s}, 1 \mathrm{H}$, -NH-). ${ }^{13} \mathrm{C}$ NMR (DMSO-d $)$ ) $\delta 149.19,149.15,143.99,139.20,138.27$, $131.46,130.93,129.81,129.07,128.62,128.48,127.28,127.19,126.92$, $125.05,124.58,123.57,121.91,106.69,102.07,64.98,59.70$. HRMS$\mathrm{ESI}+\mathrm{m} / \mathrm{z}: 420.1416[\mathrm{M}+\mathrm{H}]^{+}$.

\section{Biological assay}

MTT assay: HUVECs, PLC, HCT116, ES-2, HEPG-2 and U266 cells were respectively grown in RPMI 1640 medium containing $10 \%$ $\mathrm{FBS}$ at $37^{\circ} \mathrm{C}$ in $5 \% \mathrm{CO}_{2}$ humidified incubator. Cell proliferation was determined by the MTT (3-[4,5-dimethyl-2-thiazolyl]-2,5-diphenyl$2 \mathrm{H}$-tetrazolium bromide) assay. Briefly, cells were plated in a 96well plate at 5000 cells per well, cultured for $4 \mathrm{~h}$ in complete growth medium, then treated with serial dilutions of the compounds for 48 h. During the last $4 \mathrm{~h}, 10 \mu \mathrm{L}$ of $0.5 \%$ MTT solution was added to each well. After further incubation for $4 \mathrm{~h}$, formazan formed from MTT was extracted by adding $200 \mu \mathrm{L}$ of DMSO and mixed for $15 \mathrm{~min}$. Optical density was read with an ELISA reader at $570 \mathrm{~nm}$.

In vitro HUVECs tuber formation assay: Forty eight-well slide chambers were coated with $100 \mu \mathrm{L}$ of Matrigel (BD Biosciences, NJ) and allowed to gel at $37^{\circ} \mathrm{C}$ and $5 \% \mathrm{CO}_{2}$ for $30 \mathrm{~min}$. HUVECs were then seeded at 40,000 cells/well in M199 (5\% FBS) containing either the vehicle $(0.5 \%$ DMSO), Pazopanib or synthesized compounds and incubated at $37^{\circ} \mathrm{C}$ and $5 \% \mathrm{CO}_{2}$ for $6 \mathrm{~h}$. Themorphological changes of the cells and HUVEC tubes formation were observed under a phasecontrast microscope and photo-graphed at $\times 200$ magnification. The corresponding area was measured as the number of pixels using Adobe PhotoShop [36,37]. Experiments were repeated three times.

Rat thoracic aorta rings (TARs) assay: Forty eight-well tissue culture plates were coated with $100 \mathrm{~mL}$ of Matrigel (BD Biosciences, $\mathrm{NJ}$ ) and allowed to gel for $30 \mathrm{~min}$ at $37^{\circ} \mathrm{C}$ and $5 \% \mathrm{CO}_{2}$. Thoracic aortas were excised from 8- to 10-week-old male Sprague Dawley rats. After careful removal of fibroadipose tissues, the aortas were cut into $1 \mathrm{~mm}$ long cross-sections, placed on Matrigel-coated wells, and covered with an additional $100 \mu \mathrm{L}$ of Matrigel. After the second layer of Matrigel set, the rings were incubated for $30 \mathrm{~min}$ at $37^{\circ} \mathrm{C}$ and $5 \% \mathrm{CO}_{2}$. Aorta rings were treated every other day with either the vehicle (0.5\% DMSO), Pazopanib, or synthesized compounds for 6 days and photographed on the $7^{\text {th }}$ day at $\times 200$ magnification. The area of angiogenic sprouting, reported in the number of pixels, was quantified using Adobe Photo Shop $[36,38,39]$. Experiments were repeated three times.

\section{Results and Discussion}

\section{In vitro antiproliferative activity}

The anti-proliferation of tumor cell by compounds was determined to evaluating against ES-2, HEPG-2, U266, PLC and HCT116 cell lines by MTT assay using Pazopanib Hydrochloride as a positive control [35], and the results are summarized in Table 1. From the data shown in Table 1, most compounds was inactive with no significant inhibition of proliferation $\left(\mathrm{IC}_{50}>100 \mu \mathrm{M}\right)$, while compounds XGS-5, XGS-12, XGS-13, XGS-14 and XGS-15 exhibited moderate activity.

Comparing the data in Table 1, we obtained some following basic structure-activity relationships (SAR): (1) The size and shape of $\mathrm{R}$ group may be an important affecting factor in the anti-proliferation activities: Compounds with aromatic ring of $\mathrm{R}$ group such as phenyl and naphthyl exhibited much better inhibitory activity compared to the compounds with alkyl group of $\mathrm{R}$ group such as propyl group and ethyl. For example, compounds XGS-1, XGS-2, XGS-3 and XGS-4 showed weaker inhibition activity than compounds XGS-7, XGS9, XGS-12, XGS-13, XGS-14 and XGS-15, etc. (2) It was noteworthy that when the hydrogen of alkyl group of $\mathrm{R}$ group was replaced by halogen atoms, the compounds would be more effective (XGS-1, XGS2 vs XGS-5). (3) Disubstituted groups attached to the phenyl ring of $R$ displayed much more inhibitory performances than compounds with mono-substituted groups attached to the phenyl ring (XGS-9 vs. XGS13). (4) When the hydrogen of aromatic ring of $R$ group was replaced by electron-donating groups or weak electron-withdrawing groups, the compounds would show stronger antiproliferative activity (XGS-9, XGS-12, XGS-13 XGS-15 vs. XGS-11). However, adding nitryl group, an ultra-strong electron-withdrawing group, at the para position of phenyl leads to faint inhibition (such as XGS-11). We hypothesized compounds would show greater activity with the size increase and electron density increase of $\mathrm{R}$ group, but the severe electron density decrease of phenyl ring would make aromatic ring of $R$ group lose their structure advantage.

\section{In vitro HUVECs tuber formation assay}

Human umbilical vein endothelial cells which are induced to undergo tube formation change their architecture and develop mesh of cells that establish branched networks that take after capillary-like blood vessels. So we acquired a taste for in vitro tube formation assay using HUVECs to evaluate for the ability to inhibit angiogenesis of our target compounds. The on market anti-angiogenesis drug, Pazopanib, was selected as a positive control. As shown in Figure 1, when HUVECs were cultured on polymerized matrigel with no inhibitors, such tubelike structures took shape. However, significant inhibition (failing to 


\begin{tabular}{|c|c|c|c|c|c|c|}
\hline \multirow[t]{2}{*}{ Compd. } & \multirow[t]{2}{*}{$\mathrm{R}$} & \multicolumn{5}{|c|}{$\mathrm{IC}_{50}{ }^{\mathrm{a}}(\mu \mathrm{L})$} \\
\hline & & PLC & U266 & HEPG-2 & HCT116 & ES-2 \\
\hline XGS-1 & Methyl & $\geq 200 \pm 1.12$ & $99.69 \pm 2.31$ & $135.93 \pm 1.55$ & $\geq 200$ & $\geq 200$ \\
\hline XGS-2 & Ethyl & $\geq 200 \pm 0.87$ & $\geq 200$ & $\geq 200$ & $\geq 200$ & $\geq 200$ \\
\hline XGS-3 & n-Propyl & $193.38 \pm 0.65$ & $48.92 \pm 0.97$ & $\geq 200$ & $\geq 200$ & $130.832 \pm 0.89$ \\
\hline XGS-4 & sec-Propyl & $200 \pm 0.32$ & $85.97 \pm 0.46$ & $82.12 \pm 1.78$ & $\geq 200$ & $166.844 \pm 5.19$ \\
\hline XGS-5 & 1-Chloro-methyl & $74.54 \pm 0.73$ & $7.57 \pm 0.21$ & $29.72 \pm 0.34$ & $122.24 \pm 0.63$ & $148.49 \pm 1.98$ \\
\hline XGS-6 & 3-Nitrophenyl & $93.21 \pm 1.32$ & $103.29 \pm 0.79$ & $97.29 \pm 0.58$ & $151.31 \pm 0.076$ & $164.504 \pm 0.93$ \\
\hline XGS-7 & 3,4,5-Trimethyphenyl & $178.34 \pm 0.56$ & $39.861 \pm 0.96$ & $145.16 \pm 0.69$ & $130.47 \pm 1.39$ & $124.351 \pm 1.21$ \\
\hline XGS-8 & p-Acetamidophenyl & $176.43 \pm 0.78$ & $31.01 \pm 0.64$ & $55.65 \pm 0.77$ & $\geq 200$ & $161.167 \pm 0.33$ \\
\hline XGS-9 & 4-Fluorophenyl & $\geq 200$ & $29.49 \pm 0.57$ & $177.46 \pm 1.61$ & $125.47 \pm 1.99$ & $150.92 \pm 1.97$ \\
\hline XGS-10 & 4-Nitrophenyl & $\geq 200$ & $48.32 \pm 2.15$ & $\geq 200$ & $\geq 200$ & $\geq 200$ \\
\hline XGS-11 & Phenyl & $96.93 \pm 2.16$ & $69.18 \pm 1.57$ & $119.56 \pm 0.64$ & $\geq 200$ & $150.923 \pm 3.21$ \\
\hline XGS-12 & 4-Methoxyphenyl & $163.03 \pm 0.67$ & $1.75 \pm 0.055$ & $0.68 \pm 0.0032$ & $153.67 \pm 3.16$ & $98.524 \pm 1.34$ \\
\hline XGS-13 & 4-Bromo-2-fluorophenyl & $126.47 \pm 2.89$ & $26.27 \pm 3.42$ & $54.82 \pm 0.87$ & $114.25 \pm 0.78$ & $117.557 \pm 0.56$ \\
\hline XGS-14 & 2-Naphthyl & $113.62 \pm 1.23$ & $2.71 \pm 0.032$ & $0.75 \pm 0.045$ & $\geq 200$ & $121.535 \pm 0.64$ \\
\hline XGS-15 & 4-(1,1'-Biphenyl) & $52.89 \pm 1.54$ & $1.24 \pm 0.21$ & $0.78 \pm 0.097$ & $65.75 \pm 0.28$ & $31.24 \pm 1.69$ \\
\hline \multicolumn{2}{|r|}{ Pazopanib } & $\geq 200$ & $3.25 \pm 0.12$ & $118.47 \pm 0.67$ & $181.82 \pm 1.89$ & $\geq 200$ \\
\hline
\end{tabular}

Data represent the mean \pm SD of two experiments.

Table 1: Antiproliferative activities of compounds XGS-1 to XGS-15 and Pazopanib against five tumor cell lines.

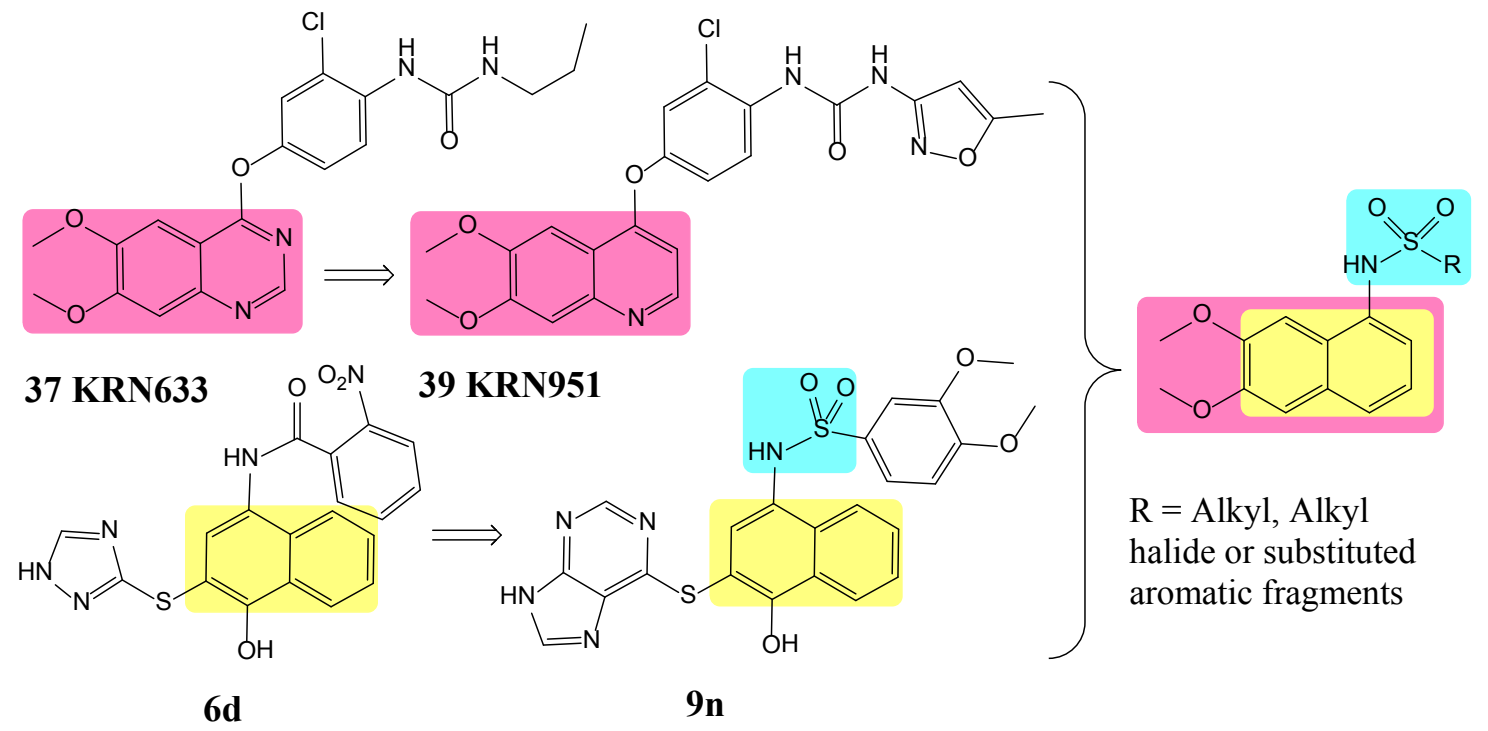

Figure 1: Strategy for the design of $N$-(6,7-dimethoxynaphthalen-yl)sulfamide derivatives.

organise into capillary-like structures) was observed with compounds XGS-5, XGS-12, XGS-13, XGS-14 and XGS-15. In order to judge whether XGS-5, XGS-12, XGS-13 XGS-14 and XGS-15 could inhibit the HUVECs planar tuber formation in a dose-dependent fashion, we set another two concentrations ( 25 and $5 \mu \mathrm{M}$ ) for further test. Gratifyingly, almost all the tested compounds exhibited concentration-dependent inhibition of tube formation (Figure 2). We found that compounds XGS-12 and XGS-15 were so effective to inhibit the tube formation at $5 \mu \mathrm{M}$ respectively, comparable to Pazopanib Hydrochloride. However, compounds XGS-5, XGS-13 and XGS-14 showed insensitivity with no significant inhibition at this concentration. Representative tube images are shown in Figure 2.

In an effort to study whether the anti-angiogenic effect of the compounds was due to conventional cytotoxic agents, we conducted a MTT assay for XGS-15 by using HUVECs. What's exciting was that compound XGS-15 exhibited weak inhibitory effects on HUVECs with high $\mathrm{IC}_{50}(>200 \mu \mathrm{M})$, so we considered the anti-angiogenic effect of compound XGS-15 was not put down to non-specific cytotoxic agents.
Hereon basis, we speculated that compound XGS-15 revealed selective cytotoxic effect on tumor cells without killing normal cells at low micromole ranges.

\section{Rat thoracic aorta rings (TARs) assay}

Relative to HUVECs tuber formation assay, TARs model has higher similarity to that in a physiological environment in view of multi-steps involved in angiogenesis: sprouting, proliferation, migration and differentiation. As a consequence, we would execute further evaluation to anti-angiogenic activity of all the potent compounds, XGS-12 and XGS-15, by TARs assay. The area of angiogenic sprouting, reported in number of pixels, was quantified using Adobe Photo Shop. The results are presented in Figure 3. Compounds XGS-12 and XGS-15 revealed prominent angiogenesis inhibition ratio at the concentration of 50 $\mu \mathrm{M}$. At $5 \mu \mathrm{M}$, compound XGS-15 demonstrated resultful inhibition of angiogenesis, comparable to Pazopanib. Nevertheless, compound XGS12 lacked inhibition of microvessel outgrowth in low concentration ( $\leq$ $12.5 \mu \mathrm{M})$. Result of aortic rings is displayed in Figure 3 . 
Pazopanib (5 $\mu \mathrm{M})$

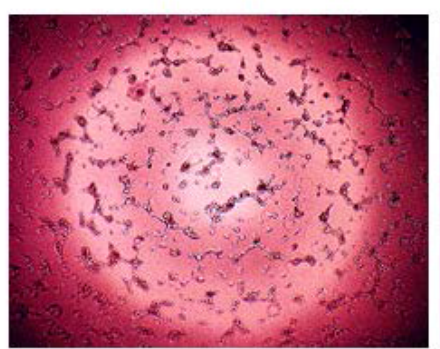

XGS-5 (5 $\mu \mathrm{M})$

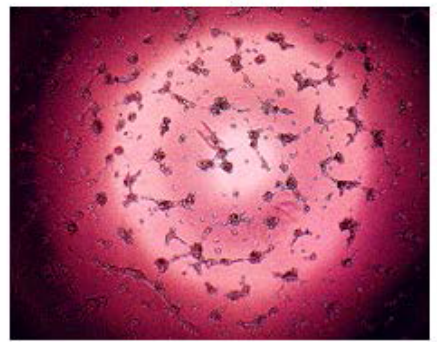

XGS-15 (5 $\mu \mathrm{M})$

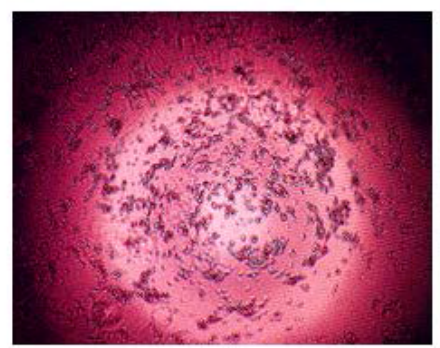

Vehicle (0.5\% DMSO)

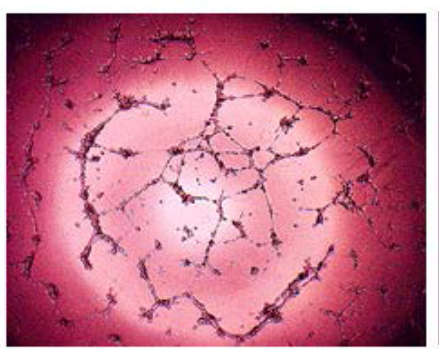

XGS-13 (5 $\mu \mathrm{M})$

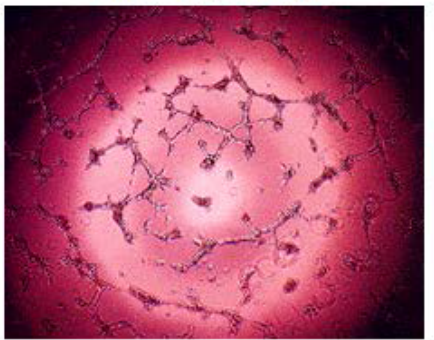

XGS-15 (25 $\mu M)$

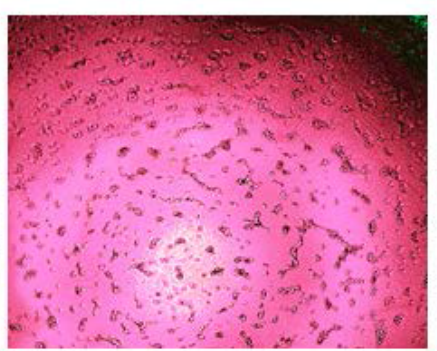

XGS-12 (5 $\mu \mathrm{M})$

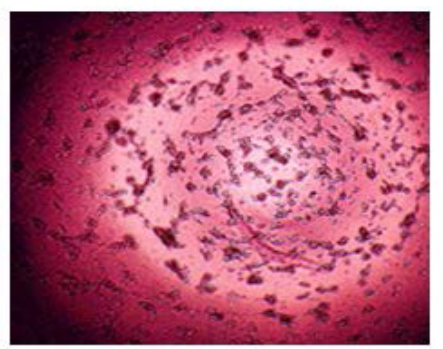

XGS-14 (5 $\mu \mathrm{M})$

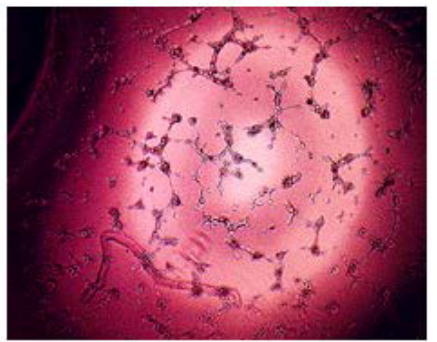

XGS-15 (50 $\mu \mathrm{M})$

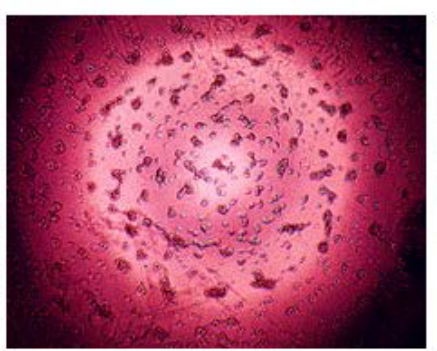

Figure 2: Representative images of the tube formation assay depicting the formation of a HUVEC capillary-like tubular network by treatment with synthesized compounds, Pazopanib (positive control) and 0.5\% DMSO (vehicle control).

Pazopanib (6.25 $\mu \mathrm{M})$

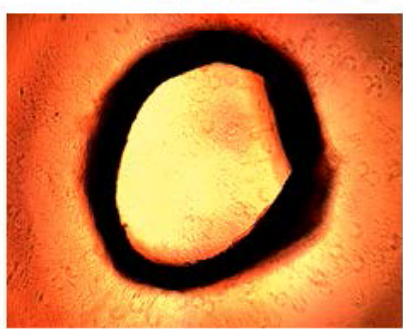

XGS-15 (6.25 $\mu \mathrm{M})$

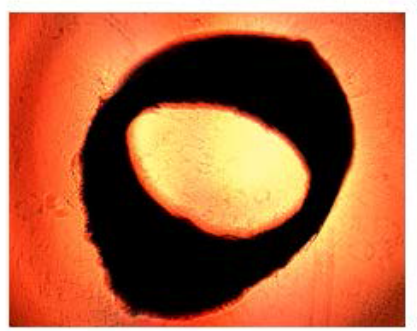

Vehicle (0.5\% DMSO)

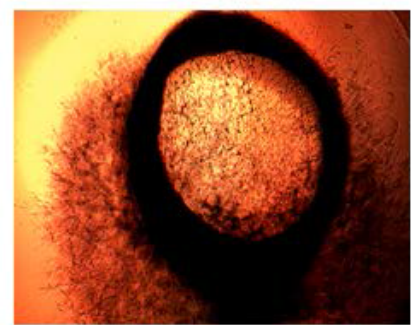

XGS-15 (12.5 $\mu \mathrm{M})$

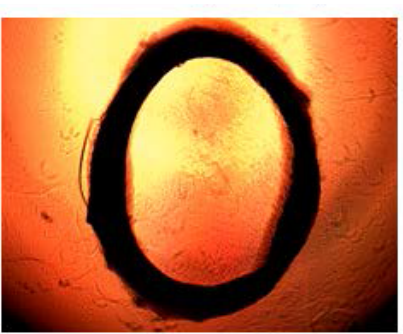

XGS-12 (6.25 $\mu \mathrm{M})$

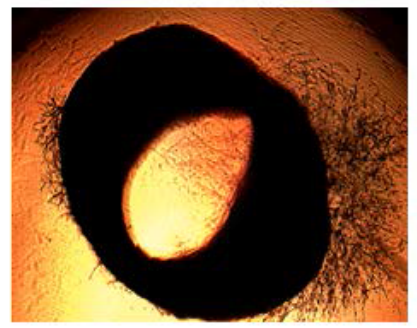

XGS-15 (25 $\mu \mathrm{M})$

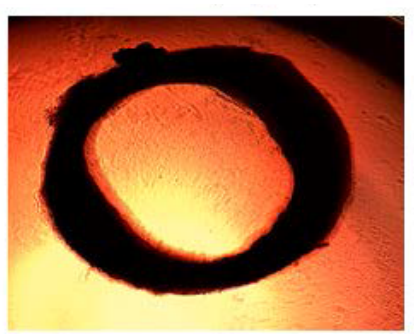

Figure 3: Representative images of rat aortic rings treated with synthesized compounds, Pazopanib (positive control) and $0.5 \%$ DMSO (vehicle control). 
Citation: Xu G, Zhou Y, Zhang S, Ma S, Xu F, et al. (2014) Synthesis and Biological Evaluation N-(6,7-dimethoxynaphthalen-yl) sulfamide Derivatives as Novel Inhibitors of Angiogenesis and Tumor Growth. Med chem 4: 598-605. doi:10.4172/2161-0444.1000200

\section{Conclusions}

To sum up, $N$-(6,7-dimethoxynaphthalen-yl)sulfamide derivatives are a series of novel scaffold provided with both anti-angiogenesis and conventional cytotoxic property for cancer treatment. The SAR demonstrated that aromatic rings and electron-donating groups on aromatic rings of $\mathrm{R}$ group are decisive factors in the antiproliferative activities. Among all the compounds, XGS-15 comprehensively manifested strong inhibition without influencing normal cells at low micromole ranges, which deserved further in vitro and in vivo studies such as kinase inhibition assay and human tumor xenograft models on its mechanism of anti-cancer therapy.

\section{Acknowledgments}

This work was supported by National Nature Science Foundation of China (grant no. 21172134), National Scientific and Technological Major Project of Ministry of Science and Technology of China (grant no. 2011ZX09401-015), and Academic Award for Doctoral Postgraduate of Ministry of Education of China (grant no.20110131110037).

\section{References}

1. Hanahan D, Weinberg RA (2000) The hallmarks of cancer. Cell 100: 57-70.

2. Shibuya M (2008) Vascular endothelial growth factor-dependent and -independent regulation of angiogenesis. BMB Rep 41: 278-286.

3. Khosravi Shahi P, Fernandez Pineda I (2008) Tumoral angiogenesis: review of the literature. Cancer Invest 26: 104-108.

4. Acheampong DO (2013) Angiogenesis and cancer therapy International, journal of pharmaceutical sciences and research 4: 2021.

5. Stival LR, Lago AM, Figueiredo MN, Bittar RH, Machado ML, et al. (2014) Efficacy and safety of subconjunctival bevacizumab for recurrent pterygium. Arq Bras Oftalmol 77: 4-7.

6. Vasudev NS, Reynolds AR (2014) Anti-angiogenic therapy for cancer: current progress, unresolved questions and future directions. Angiogenesis 17: 471494.

7. Grant SK (2009) Therapeutic protein kinase inhibitors. See comment in PubMed Commons below Cell Mol Life Sci 66: 1163-1177.

8. Folkman J (2007) Angiogenesis: an organizing principle for drug discovery? Nat Rev Drug Discov 6: 273-286.

9. Browder T, Butterfield CE, Kraling BM, Shi B, Marshall B, et al. (2000) Antiangiogenic scheduling of chemotherapy improves efficacy against experimental drug-resistant cancer. Cancer Res 60: 1878-1886.

10. Bello E, Taraboletti G, Colella G, Zucchetti M, Forestieri D, et al. (2013) The tyrosine kinase inhibitor E-3810 combined with paclitaxel inhibits the growth of advanced-stage triple-negative breast cancer xenografts. Mol Cancer Ther 12: $131-140$

11. Dhanabala M, Volkb R, Ramchandrana R, Simonsb M, Sukhatme VP (1999) Cloning, Expression, andin VitroActivity of Human Endostatin. Biochem Biophys Res Commun 10: 345-352.

12. Izzedine H, Buhaescu I, Rixe O, Deray G (2007) Sunitinib malate. Cancer Chemother Pharmacol 60: 357-364.

13. O'Farrell AM, Foran JM, Fiedler W, Serve H, Paquette RL, et al. (2003) An innovative phase I clinical study demonstrates inhibition of FLT3 phosphorylation by SU11248 in acute myeloid leukemia patients. Clinical Cancer Research 9 : 5465-5476.

14. Hasskarl J (2010) Sorafenib. Recent Results Cancer Res 184: 61-70.

15. Li BX, Xiao X (2009) Discovery of a small-molecule inhibitor of the KIX-KID interaction. Chembiochem 10: 2721-2724.

16. Kaku T, Hitaka T, Ojida A, Matsunaga N, Adachi M, et al. (2011) Discovery of orteronel (TAK-700), a naphthylmethylimidazole derivative, as a highly selective 17,20-lyase inhibitor with potential utility in the treatment of prostate cancer. Bioorganic \& Medicinal Chemistry 19: 6383-6399.

17. Ge Y, Kazi A, Marsilio F, Luo Y, Jain S, et al. (2012) Discovery and synthesis of hydronaphthoquinones as novel proteasome inhibitors. J Med Chem 55: 1978-
1998.

18. Qin J, Xie P, Ventocilla C, Zhou G, Vultur A, et al. (2012) Identification of a novel family of BRAF(V600E) inhibitors. J Med Chem 55: 5220-5230.

19. Xu F, Jia Y, Wen Q, Wang X, Zhang L, et al. (2013) Synthesis and biological evaluation of $\mathrm{N}$-(4-hydroxy-3-mercaptonaphthalen-1-yl)amides as inhibitors of angiogenesis and tumor growth. Eur J Med Chem 64: 377-388.

20. Xu F, Xu H, Wang X, Zhang L, Wen Q, et al. (2014) Discovery of N-(3-((7H-purin6-yl)thio)-4-hydroxynaphthalen-1-yl) -sulfonamide derivatives as novel protein kinase and angiogenesis inhibitors for the treatment of cancer: Synthesis and biological evaluation. Part III. Bioorganic \& Medicinal Chemistry 22:1487-1495

21. Habeeb AG, Praveen Rao PN, Knaus EE (2001) Design and synthesis of celecoxib and rofecoxib analogues as selective cyclooxygenase-2 (COX-2) inhibitors: replacement of sulfonamide and methylsulfonyl pharmacophores by an azido bioisostere. J Med Chem 44: 3039-3042.

22. Julémont $F$, de Leval $X$, Michaux $C$, Damas J, Charlier $C$, et al. (2002) Spectral and crystallographic study of pyridinic analogues of nimesulide: determination of the active form of methanesulfonamides as COX-2 selective inhibitors. J Med Chem 45: 5182-5185.

23. El-Sayed NS, El-Bendary ER, El-Ashry SM, El-Kerdawy MM (2011) Synthesis and antitumor activity of new sulfonamide derivatives of thiadiazolo[3,2-a] pyrimidines. Eur J Med Chem 46: 3714-3720.

24. Kamal A, Dastagiri D, Ramaiah MJ, Reddy JS, Bharathi EV, et al. (2011) Synthesis and apoptosis inducing ability of new anilino substituted pyrimidine sulfonamides as potential anticancer agents. Eur J Med Chem 46: 5817-5824.

25. Henn C, Einspanier A, Marchais-Oberwinkler S, Frotscher M, Hartmann RW (2012) Lead optimization of 17ß-HSD1 inhibitors of the (hydroxyphenyl) naphthol sulfonamide type for the treatment of endometriosis. J Med Chem 55: 3307-3318.

26. Dumas J, Smith RA, Lowinger TB (2004) Recent developments in the discovery of protein kinase inhibitors from the urea class. Curr Opin Drug Discov Deve 7: 600-616.

27. Nakamura K, Yamamoto A, Kamishohara M, Takahashi K, Taguchi E, et al. (2004) KRN633: a selective inhibitor of vascular endothelial growth factor receptor-2 tyrosine kinase that suppresses tumor angiogenesis and growth Mol Cancer Ther 3: 1639-1649.

28. Matsunaga N, Nakamura K, Yamamoto A, Taguchi E, Tsunoda H, et al. (2006) Improvement by solid dispersion of the bioavailability of KRN633, a selective inhibitor of VEGF receptor-2 tyrosine kinase, and identification of its potential therapeutic window. Mol Cancer Ther 5: 80-88.

29. Nakamura K, Taguchi E, Miura T, Yamamoto A, Takahashi K, et al. (2006) KRN951, a highly potent inhibitor of vascular endothelial growth factor receptor tyrosine kinases, has antitumor activities and affects functional vascular properties. Cancer Res 66: 9134

30. Eskens FA, Planting A, Van Doorn L, Isoe T, Hayashi K, et al. (2006) An openlabel phase I dose escalation study of KRN95, a tyrosine kinase inhibitor of vascular endothelial growth factor receptor 2 and 1 in a 4 week on, 2 week off schedule in patients with advanced solid tumors. J Clin Oncol 24: 2034.

31. Sonpavde G, Hutson TE (2007) Pazopanib: a novel multitargeted tyrosine kinase inhibitor. Curr Oncol Rep 9: 115-119.

32. Ricotta R, Di Bella S (2014) Outcomes of patients with metastatic renal cel carcinoma treated with pazopanib in daily clinical practice: a single institution experience. See comment in PubMed Commons below Tumori 100: 87e-91e.

33. Ng SS, Gutschow M, Weiss M, Hauschildt S, Teubert U, et al. (2003) Antiangiogenic activity of $\mathrm{N}$-substituted and tetrafluorinated thalidomide analogues. Cancer Res 63: 3189-3194.

34. Krystof V, Rarova L, Liebl J, Zahler S, Jorda R, et al. (2011) The selective P-TEFb inhibitor CAN508 targets angiogenesis. Eur J Med Chem 46: 42894294.

35. Go RS, Ritman EL, Owen WG (2003) Angiogenesis in rat aortic rings stimulated by very low concentrations of serum and plasma. Angiogenesis 6: 25-29.

36. Stermitz FR, Gillespie JP, Amoros LG, Romero R, Stermitz TA, et al. (1975) Synthesis and biological activity of some antitumor benzophenanthridinium salts. J Med Chem 18: 708-713.

37. Lee MH, Han JH, Kwon PS, Bhuniya S, Kim JY, et al. (2012) Hepatocytetargeting single galactose-appended naphthalimide: a tool for intracellular thio imaging in vivo J Am Chem Soc 134: 1316-1322. 
Citation: Xu G, Zhou Y, Zhang S, Ma S, Xu F, et al. (2014) Synthesis and Biological Evaluation N-(6,7-dimethoxynaphthalen-yl) sulfamide Derivatives as Novel Inhibitors of Angiogenesis and Tumor Growth. Med chem 4: 598-605. doi:10.4172/2161-0444.1000200

38. Ichinose W, Miyagawa M, Ito J, Shigeno M, Amemiya R, et al. (2011) Synthesis and duplex formation of the reverse amidohelicene tetramer. Tetrahedron 67: 5477-5486.
39. Mosmann T (1983) Rapid colorimetric assay for cellular growth and survival: application to proliferation and cytotoxicity assays. J Immunol Methods 65: 5563. 